\title{
Right hip pain in a 20-year-old epee fencer
}

\author{
Catherine N. Petchprapa • Jenny T. Bencardino • \\ Robert J. Meislin
}

Received: 12 July 2011 /Revised: 11 October 2011 /Accepted: 19 October 2011 /Published online: 24 December 2011

(C) ISS 2011

Part I A 20-year-old woman presented with 3 months of hip pain. She is on the Olympic developmental squad for epee fencing and states that the pain involves the leading leg when she lunges. She has full range of motion but positive impingement signs on physical exam. AP, frog lateral and
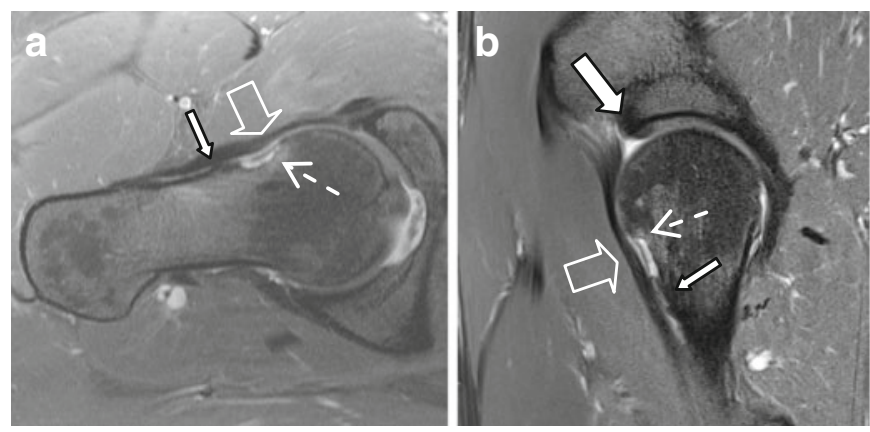

Fig. 1 Axial oblique (a) and sagittal (b) fat-suppressed PD iMRA, and proton density-weighted radial (c) image through the 10:30 position of the anterosuperior labrum. Depressed cortical impaction (open arrow) with marrow edema (dotted arrow) along the anterior femoral head-neck junction and relative thickening of the subjacent neck cortex (thin white arrow) are seen in $\mathbf{a}$ and $\mathbf{b}$. Amputated tear of

The diagnosis can be found at doi:10.1007/s00256-011-1315-z.

C. N. Petchprapa $(\bowtie) \cdot$ J. T. Bencardino

Department of Radiology, NYU Langone Medical Center -

Hospital for Joint Diseases,

6th floor, 301 East 17th Street,

New York, NY 10003, USA

e-mail: petchc01@nyumc.org

\section{R. J. Meislin}

Department of Orthopedics, NYU Langone Medical

Center - Hospital for Joint Diseases,

301 East 17th Street,

New York, NY 10003, USA cross table lateral views of the right hip as well as indirect MR arthrography (iMRA) of the left hip were obtained (Fig. 1).

Conflict of interest The authors declare that they have no conflict of interest.
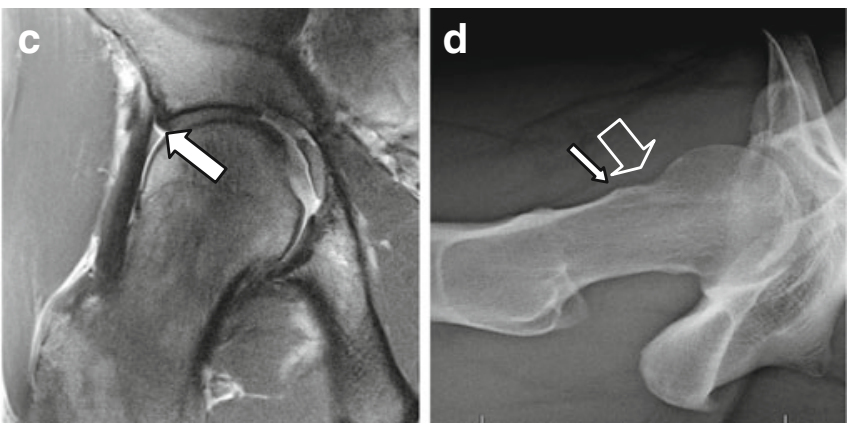

the anterior superior labrum (thick white arrow) opposite the notch on sagittal (b) image and radial image (c). The tear extended from $10-$ 11:00. d Cross table lateral radiograph of right hip. Both the impaction injury (open arrow) and reactive cortical thickening (thin white arrow) are seen on plain radiograph. The patient did not have radiographic cam or pincer deformity 